\title{
A perspective on multi-user interaction design based on an understanding of domestic lighting conflicts
}

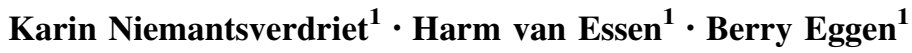

Received: 27 May 2016/ Accepted: 15 December 2016/Published online: 4 January 2017

(C) The Author(s) 2017. This article is published with open access at Springerlink.com

\begin{abstract}
More and more connected systems are entering the social and shared home environment. Interaction with these systems is often rather individual and based on personal preferences, leading to conflicts in multi-user situations. In this paper, we aim to develop a perspective on how to design for multi-user interaction with connected lighting systems, based on a better understanding of reallife interpersonal lighting conflicts. In order to understand everyday lighting conflicts, including their causes and resolution strategies, we present two studies. First, we observe real-life lighting conflicts between couples living in single-room apartments. Using probes for data gathering followed by dyadic interviews, we identify the role of agreements on use in conflicts and we identify different types of conflicts (preference, activity, and attitude conflicts). Next, we take a more disruptive approach based on technology probes, where we provoke lighting conflicts in family living rooms to observe resolution strategies. We find that people try to avoid conflicts at all costs. If there is a risk that others are negatively affected by an adjustment, people rather not interact with the system at all. Based on these insights, we defined a perspective on designing for multi-user interaction that provides the user with the confidence that interactions are socially accepted. This
\end{abstract}

Karin Niemantsverdriet

k.niemantsverdriet@tue.nl

Harm van Essen

h.a.v.essen@tue.nl

Berry Eggen

j.h.eggen@tue.nl

1 Department of Industrial Design, Eindhoven University of Technology, Den Dolech 2, 5612 AZ Eindhoven, The Netherlands assurance can be given by presenting the user with information leading to awareness about the acceptance of a lighting change by the other users. We advise on what information can be visualized, based on the three conflict types we observed in the study. The combination of a deeper understanding of conflicts and a perspective on multi-user interface design can serve as a starting point to design better multi-user interfaces for domestic connected systems.

Keywords Multi-user interaction - Interaction design · Lighting conflicts · Conflict resolution · Connected lighting systems · Home environment - Internet of things - Smart home

\section{Introduction}

Enabled by developments like Internet of Things, connected systems are increasingly appearing in the home environment. Recent examples include wireless speakers [1, 2], home security systems [3], smart thermostats [4], and networked lighting systems $[3,5,6]$. These systems are characterized by their ability to connect different devices and information sources (such as sensors or databases storing personal preferences and use patterns) to provide more dynamic and customized services. While alternative interaction styles are being developed (e.g., [7, 8]), currently, most interaction with these connected systems is through mobile phones applications. Mobile phones, with their computing power, mobility, and omnipresence, offer a highly advanced and available platform for interaction designers. But the use of, e.g., sensor data, customized interfaces, and individual presets or playlists makes the interaction highly individual [9]. The home is, in contrast, a 
social environment, inhabited by families, roommates, or couples. Interaction paradigms that are based on individuals are bound to result in conflicts in a multi-user setting, since interaction design influences the style of cooperation through its affordances: "If designers ignore issues of conflict in the explicit part of the design, then their underlying assumptions about conflict, or its absence, become embedded in the system." ([10], p. 2) We therefore argue that designing interaction for domestic connected systems requires a multi-user perspective that is informed by an understanding of conflict in the home environment.

An interesting example of connected systems for the home environment is networked lighting systems (e.g., $[3,5,6])$. In lighting, next to networking technology, developments in LED technology have opened up a world of new digitally manipulable parameters, such as brightness, color, color temperature, and dynamics [11]. The benefits are clear: because of the long-studied influence of light on well-being, productivity, and social behavior $[12,13]$ flexible and manipulable lighting makes it possible to have lighting conditions that better support people's varying activities. However, in a family living room where different people (e.g., family members, guests, baby sitters) simultaneously perform many different activities that could all potentially benefit from different light settings (e.g., cooking, playing, studying, reading, watching TV), finding an optimal lighting condition can become rather complicated.

Similar to other connected systems, interaction paradigms for lighting are highly individual: people can create personal lighting conditions (called scenes, presets, or moods) or program specific interaction rules for automated system behavior, that, for example, turn the lamps on when their mobile phone connects to the local Wi-fi network. This highly individual interaction with modern lighting systems brings up issues in the multi-user home context $[11,14]$. For example, the relatively effortful creation of presets and behavior rules do not invite for everyone to participate equally in the interaction: usually, there is one main user that decides on the interaction for others. Also, the individual customization of scenes (that are generally not sharable with other users) puts no emphasis on taking the needs and wishes of other users into consideration. Moreover, differences in network connectivity (e.g., of guests and children) are likely to result in misinformed systems (e.g., when lights automatically turn off because the main user leaves the house even though other people might still be present). We argue that this type of conflicts can and should be avoided, by taking them into account in the interaction design process.

Research suggests that without mediating technology, people resolve conflicts by discussion or by yielding privilege over certain systems $[10,15]$. While this is recognizable in, for example, contention about which television program to watch, lighting wishes seem less of a discussion topic in daily life. In development of Home Automation Systems, scenarios have been proposed where intelligent conflict managers recognize and resolve conflicts automatically by comparing user preferences: people's ratings for certain lighting conditions given a certain context that are stored in user profiles (e.g., [16-21]). Research from cognitive psychology, however, shows that preferences are constructed in the moment instead of elicited from memory [22], which makes them less static than the preference ratings in user profiles suggest. Also, incontext research on lighting use by Offermans et al. [23] has shown that people's lighting needs and preferences are mainly latent and that they depend heavily on the environment, people's intentions with the environment, and the social context. So it seems that current strategies to handle conflicts underestimate the complexity of preference elicitation, which makes it unlikely that their identification and resolution of conflicts matches the social setting. Furthermore, most of the current strategies are based on hypothetical lighting conflict scenarios instead of on examples resulting from real-life observations. In line with (e.g., [24-26]), we believe that technological developments in the home should be based on in-context research in the home environment. So in order to design multi-user interfaces that handle conflicts in a socially acceptable way comparable to people's natural behavior, we first need to get a better understanding of real-life multi-user conflicts.

In this work, we aim to propose a perspective on multiuser interaction paradigms for domestic lighting systems that fit people's natural ways of using light and resolving conflicts. To inform such a perspective, a deeper understanding is needed of everyday lighting conflicts as they take place in the home environment. We want to identify real-life triggers for conflicts and we want to observe people's resolution strategies. To do so, we conduct two explorative, ethnographically inspired studies. The two studies differ in their aims. In the first study, we aim to identify real-life lighting conflict scenarios between couples living in single-room apartments. We do so through a probe package to sensitize people for their normal lighting routines, followed by dyadic interviews. In the second study, we create the trigger for conflict so we can study people's resolution strategies. This more disruptive approach is based on technology probes [27, 28]. By installing a connected lighting system in family living rooms where all family members influence each other with every adjustment, we provoke lighting conflicts. This allows us to observe resolution strategies that people deploy. We combine the insights from the two studies to define a perspective on how to design for multi-user interaction with domestic lighting systems. The perspective 
can be used to design interfaces for domestic connected lighting systems that are based on how people handle conflicts in their everyday lives.

\section{Related work}

We aim to develop an understanding of real-life lighting conflicts, in order to develop a perspective on how to design for multi-user interaction with domestic lighting systems. Therefore, our related work is focused on three main topics: conflict, home technology sharing, and lighting interaction. Most of the work on conflicts either comes from social psychology and has a very broad scope, beyond system interaction; or comes from computer science and approaches conflicts and conflict resolution from an automated system perspective. The human perspective that is more related to our approach originates from ethnographic research on home technology sharing. Lastly, we look at our specific application domain and discuss the current state of lighting interaction and the understanding of domestic lighting use.

\subsection{Conflicts and conflict resolution}

In line with Putnam and Poole (as cited in [10], p. 2), we use a broad definition of conflict as "the interaction of interdependent people who perceive opposition of goals, aims, and values, and who see the other party as potentially interfering with the realization of these goals... [This] definition highlights three general characteristics of conflict: interaction, interdependence, and incompatible goals." In the field of social psychology conflict has received much attention but the types of questions and results are often not directly applicable to interaction design. However, the three characteristics clearly emphasize the interplay between system design and the occurrence of conflict. Conflict has different stages. It starts with latent conflict, where the conflict is there but where the parties are not aware of its existence. A perceived conflict is noticed by some or all parties but is not explicated like a manifest conflict is [10]. We expect, based on the findings by Offermans et al. [23], that in lighting many conflicts remain latent. Interestingly, Deutsch found that conflict is not necessarily negative: conflict can be productive in the sense that it can stimulate curiosity, prevents stagnation, and leads to social change [29].

Conflicts in computer science are usually approached from a technical perspective and include any type of conflicting state that can occur within a system. So conflicts could result from multiple users with different preferences, from multiple applications within one system concurring over a resource (e.g., different applications trying to control the light based on Web information flow, occupancy, and an activity-based preset, at the same time), or from conflicting interests within one user (a person might have interest in both high lighting quality and minimizing energy consumption), among others. There are different ways to classify all these conflicts. Al-Bin Ali [16] classifies conflicts in terms of their technical recognizability: explicit conflicts are directly identifiable by a system by examining behaviors, while implicit conflicts result from more "hidden factors," such as moods and human intentions. Since our studies take a human perspective rather than a system perspective, recognizing conflicts from a system perspective is of less use to us. Resendes et al. [30] propose four different classifications of conflicts based on his extensive review of Home and Building Automation Systems (HBAS): classification based on source, time of detection, solvability, or intervenient. The interpersonal conflicts (or in Resendes' words user vs. user conflicts) that we look at in this paper are only a small part of the intervenient class. Deutsch [29] identifies conflicts based on their causes: inequality of control over resources, difference in preferences and nuisance, a difference in values, dispute over beliefs, or the nature of the relationship between parties. This classification seems most applicable to our intended results but remains too abstract to directly inform a design perspective.

Resolution strategies for interpersonal conflicts are often based upon systems keeping track of user profiles by storing user ratings of a certain setting as a preference. Common resolution strategies mediate between users through, e.g., Profile Merging, where a common user profile is generated from the individual user profiles through a distance minimization algorithm (e.g., [17, 19, 20]). Alternatively, a user could be given priority over resources through, e.g., Weighted Alternative, taking into account weight or importance for each preference or Majority rule, where votes are counted [31]. This priority could be provided spatially (so per luminaire, e.g., [21]) or temporally (e.g., [18]). Examples are available of systems that resolve conflicts completely automatically (e.g., [20]), but the majority of system proposals use a combination of automated decisions for explicit conflicts (that can be recognized by the systems) and user control for implicit conflicts (that are more difficult to be recognized). This control is often given by asking the user for input at the moment of conflict, by presenting different recommended settings (e.g., $[16,21])$. More recently, the idea to give end users tools to program their environment on forehand is also explored. Through simple trigger-action programming (if this, than that), it is envisioned that users could customize their automated systems [32, 33] and provide compromise rules even before conflicts arise. 
The importance of full user control has also been underlined, especially within the lighting domain. Meerbeek et al. [34] performed a large field study with automatically controlled venetian blind systems with options for manual override. In three of their four identified use profiles, people are not satisfied with the automatic mode and switch it off completely. This is in line with findings by Veitch [35], which describe how the perception of control positively influences people's perceived lighting quality and satisfaction with the lighting and the environment. With our study, we aim to develop a new perspective on addressing conflict resolution in lighting interaction, based on our observations of people's natural resolution strategies.

\subsection{Home technology sharing}

Ethnographically inspired research has been done on technology sharing in the home context. Most of these studies were performed between 1995 and 2005 and focus primarily on the shared use of personal computers (e.g., $[36,37])$. In these studies, contention for computer time was seen as a main issue and parents often regulated computer usage and Internet access among family members. Also, location of the technology was found to be important to predict the sharing behavior and ownership over the technologies [38]. Some studies also focused on other types of domestic appliances. For example, Chetty et al. [39] created the Home Watcher: a domestic tool that can be used to coordinate bandwidth sharing in family homes, Crabtree and Rodden [40] researched communication between family members in daily routines, Brush and Inkpen [38] investigated sharing of all technology between family members through interviews, and Randal [41] performed a case study on living in a smart home.

An important topic in shared technology is the continuum between personalization (adjusted to the individual) and integration (open for all family members) [41]. Corresponding models to mediate sharing are identified by Brush and Inkpen [38]: the appliance model and the profile model. Devices based on an appliance model can be used by anyone and rely on social protocols to mediate sharing (e.g., shared TVs, refrigerators, and traditional lamps). Devices that use the profile model, ask individual users to identify themselves (e.g., shared desktop computers). At the time that the research was conducted, the profile model was only used in shared desktop computers, but it seems that smartphone interfaces bring many more profile-based devices into the home. Based on an investigation of sharing of a broad range of household technologies, Brush and Inkpen [38] propose a mixed model that combines a single profile that is shared by everyone but that can switch toward individual profiles in an activity. Such a mixed model would support awareness and quick interactions, but would still allow for personalization. They also mention that profiles are not so much used for privacy, but rather for regulation and personalization of features in the home. They therefore propose to use skins instead of profiles that provide personalization while allowing access to shared documents and shared information.

Crabtree and Rodden [40] researched communication between family members in daily routines. They found that communication between family members is facilitated by an ecological network of displays that people construct to coordinate actions among each other (think of refrigerator notes and post-it boards). Similarly, Taylor et al. [42] showed that people use information clues to coordinate behavior among each other. They argue that "it is people that induce their homes with intelligence by continually weaving together things in their physical worlds with their everyday routines and distinct social arrangements." ([42], p. 383). The smartness of objects, in their view, lies in the way that people use and arrange the objects in the physical world: by arrangements of notes, for example, it is clear which messages matter when, or for whom they are to see. The methodology and the real-life perspective in these studies are much related to the work we present in this paper. However, we specifically focus on interaction with lighting systems.

\subsection{Lighting interaction}

Next to the large number of applications for interaction with connected lighting systems, some examples of dedicated lighting interfaces are appearing. The commercially available Hue tab [7] is a wall-mounted interface with three buttons for three different presets. The Goldee wallmounted interface [43] recognizes gesture interactions to switch between different types of system behaviors. Fonckel One [44] integrates the interaction with the light source, to provide more direct manipulation of the light through touch gestures. Both Goldee and Fonckel are not commercially continued but provide compelling examples of gesture interfaces for lighting. Interface concepts also result from research work. Lucero et al. [11] present a number of interaction design challenges for lighting interaction, together with an overview of lighting interaction concepts. With M-beam [45], a light beam can be physically manipulated to represent a certain mood. Ross and Keyson [46] present an expressive interface in which people can "sculpt atmospheres": manipulate light, sound, and projects in one through tangible interaction with flags on a rotating platform. The Reality Editor [47] explores the use of augmented reality techniques to map graphical user interface elements directly on top of the controlled lamp. And Bakker and Niemantsverdriet [48] present four 
lighting interfaces that can potentially be interacted with the periphery of attention.

In terms of multi-user interaction, the challenges multiple for lighting interaction design, including potential conflicts and distribution of control, have been emphasized [11], but answers on how to tackle these challenges are rare. Early smart home research has investigated which general interaction modalities would be most suitable for lighting interaction in the home context. For example, Brumitt et al. [49] investigated different interfaces (including voice recognition, graphical user interfaces, and automatic behavior) by inviting families into the Easy Living home lab [50] and found that speech-controlled interaction would be most suitable. However, while families were invited for this study, participants interacted individually with the different interfaces so multi-user implications were not represented in the results [49]. One of the very few examples of lighting interaction specifically designed for and evaluated with multiple users, is found in work by Magielse et al. [12]. They explored how three different control structures (individual, shared, and hierarchical) in lighting interfaces influenced the behavior of participants in a discussion. The results were translated into the design of a light controller for the office environment, which allows for both individual and shared control over certain luminaires.

All the interaction examples mentioned explore new lighting interaction paradigms but most of these present one very specific design example. In this work, we aim toward developing a perspective on multi-user lighting interaction for the home environment in general, rather than developing specific interfaces for specific situations.

\subsection{Understanding domestic lighting use}

With respect to understanding real-life domestic lighting use, most related to the work presented in this paper is the study done by Offermans et al. [23] and Lucero et al. [51]. Offermans and colleagues investigate the needs, wishes, and motivations for interaction with lighting in the home environment. Their insights show that people mainly have latent lighting needs that are highly dependent on the context and that people have different levels of lighting needs which require control at different levels as well. They also identify a relation between the lighting interface and the motivation to interact with the light; based on degrees of freedom, availability of the controller, the degree of automation, and the qualities of the interaction. While some of the insights touch upon multi-user issues in the home environment, the work by Offermans et al. was mainly focused on the needs of individuals. With the work that we present in this paper, we take a similar approach to identify multi-user conflicts within the home environment.
Lucero et al. [51] also take a probe-based approach to investigate design requirements for a multi-user lighting system for the bathroom environment. They found that people rather deal with conflicts themselves, instead of having a system mediate in preferences and therefore shift their focus to reducing the complexity of interaction with lighting systems. We agree (in line with the literature presented in Sect. 2.1) that full system mediation would be undesired. With this work, we would like to get better grip on what strategies people apply for conflict mediation in daily life and how they can be supported in resolving lighting conflicts in a satisfactory manner.

In the following sections, we present the two studies that are aimed to identify triggers and resolution strategies of lighting conflicts in different types of home environment. After that, we will use the insights to describe our perspective on designing for multi-user interaction with domestic lighting systems.

\section{Observing conflicts between partners in a single- room apartment}

With this first study that we present, we aim to get a better understanding of the role of lighting conflicts in everyday interaction. We want to identify realistic lighting conflict scenarios and the triggers for these conflicts. We also aim to gain insights on the impact that conflicts have on the social setting and the resolution strategies that people deploy. Since the home environment is difficult to observe first hand and since interacting with lighting is usually done unaware [23], we make use probes from a perspective of information gathering [52] or data collection [53]. Probes provide a way to gather data about a person's context through exercises and self-documentation in order to frame new challenges, inspire design, and create a dialogue. In our study, the exercises in the probe set (Fig. 1) are used to sensitize the participants about their personal lighting use, in order to get more detailed answers in a dyadic interview. This use of probes is known from context-mapping studies [54].

\subsection{Study setup}

In this study, eight participants (four couples) living in single-room apartments took part. In single-room apartments there is only one space in which all activities take place, which means that people are always influenced by each other's light settings. We expect this to lead to a higher number of observable conflicts. All four couples live in two duplicate neighbor buildings in Eindhoven, The Netherlands. The buildings are newly renovated and have a relatively homogenous group of renters: young couples 


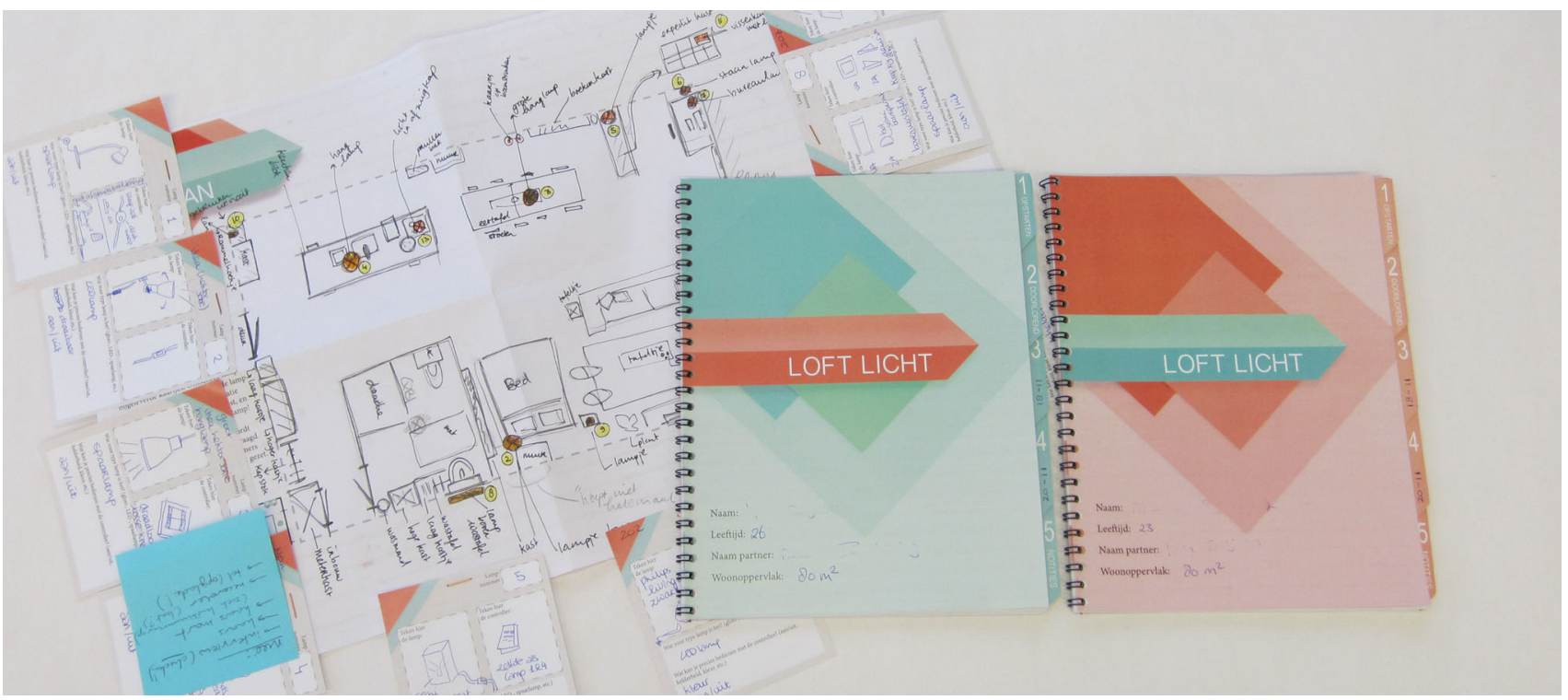

Fig. 1 Probe set, consisting of two workbooks and a floor plan

with work in the creative industries and medium income. The couples that participated in this study are all mixedgender and are aged between 23 and 27 (median $=25$ ). They all recently started living together ( $\max 1,5$ years). Recruitment was done by acquaintance and through the building's Facebook page. The study was performed in November and December of 2014. During these months, the sun rises around 8:30 a.m. and sets around 4:30 p.m., so there is a maximal need for artificial lighting.

\subsubsection{Procedure}

The probe set consists of two workbooks, one per person, containing playful exercises (Fig. 1). The workbooks serve two purposes: (1) to make the participants aware of their usage, control, and preferences in light (sensitizing); and (2) to find differences in answers between the two partners. Participants had 7-10 days to fill in the exercises, after which the study was concluded with a dyadic interview. The workbooks were all in Dutch. One of the interviews was in English, since one of the participants-although able to do the exercises in Dutch-was more comfortable with speaking English. All other interviews were in Dutch.

The workbooks consist of three different types of exercises: (1) startup exercises to get people acquainted to the topic of lighting use (e.g., drawing a map of the house and indicating the main use and satisfaction of each lamp); (2) exercises about specific events that happened during the week of the study (e.g., conversations, disagreements, and habitual light settings for certain activities); and (3) exercises that have to be made on a specific date (e.g., a timeline exercise). See Fig. 2 for an impression of the exercises.
To prepare for the interview, we collected the booklets two days before and we analyzed the results by comparing the answers between the two partners. The interviews were held in the apartments of the couple, took 50-80 min, and followed a semi-structured approach. We asked people about their evaluation of the overall lighting setup, about how they selected their lighting and lamps, and about their lighting requirements. We also asked about lighting routines and usage, and about living in single-room apartments in general. Furthermore, we asked about specific differences between the answers in the two workbooks. Participation in this study was completely voluntarily. Participants only received a symbolic token of appreciation for their participation in the study.

\subsubsection{Analysis}

From the transcribed interview recordings, 199 fragments were extracted (between 37 and 66 per interview) by reading through the printed-out interviews multiple times and marking all relevant passages. The relevant passages were cut out and used in an inductive thematic analysis [55]. We started by clustering quotes into general clusters, and we divided each topic into smaller and more specific sub-themes. The clustering process was done iteratively and resulted in a total of six themes (see Table 1). In discussions among all authors, we looked for recurring patterns within each theme. In the following section, we present the findings and illustrate them with quotes from the interview and workbook. Since all researchers are native Dutch speakers the analysis was done in Dutch. The quotes that are presented in this paper were translated after analysis by the authors. 


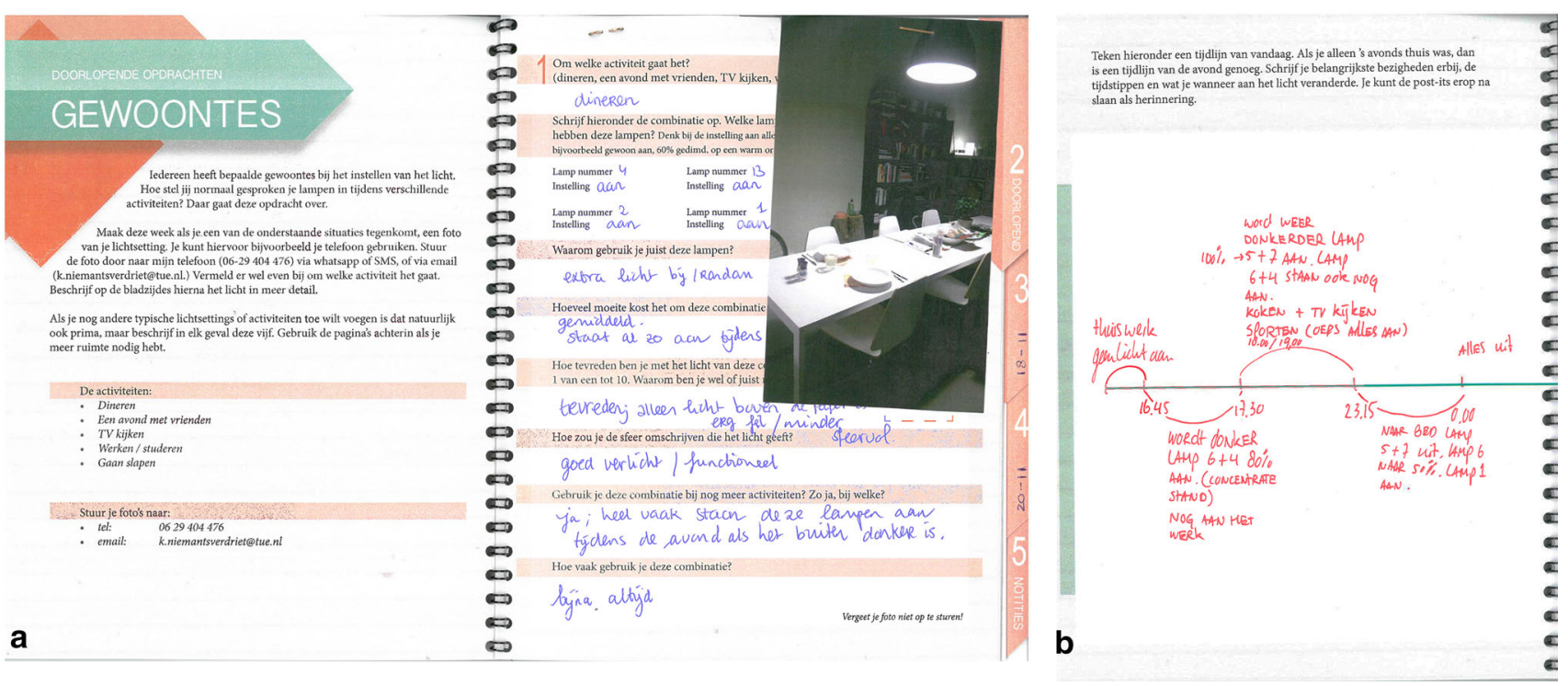

Fig. 2 Some exercises from the workbook (in Dutch): a the exercise about habitual light settings for different activities (this one shows a photo of the dinner setting), and $\mathbf{b}$ showing half of the timeline exercise, where people report their activities and their lighting adjustments during one specific day (e.g., "working at home without any lights on," and "It's getting dark, lamp $6+4$ on for $80 \%$ (concentration setting). Still working")

Table 1 An overview of the themes resulting from the thematic analysis. The table presents the theme, the number of quotes per theme (\#), how many of the four households are represented in the theme (spread), and an example quote

\begin{tabular}{|c|c|c|c|}
\hline Theme & \# & Spread & Example quote \\
\hline Lighting conflicts & 27 & $4 / 4$ & $\begin{array}{l}\text { 2A: I need some light, otherwise I get the feeling that it is night and that I should be sleeping. But that } \\
\text { is a general thing: you want it darker and I want it lighter }\end{array}$ \\
\hline Conflict resolution & 22 & $4 / 4$ & $\begin{array}{l}\text { 2A: There are some settings where we take each other into account. For example when I go to bed } \\
\text { earlier and you turn the lights down a bit as a compromise }\end{array}$ \\
\hline Importance of light & 14 & $3 / 4$ & 2A: It is just not that important. Usually, I just turn on a setting and that is all \\
\hline Single-room apartments & 16 & $4 / 4$ & $\begin{array}{l}\text { 2B: I guess everyone thinks about [being able to live in one space] before moving here. We also } \\
\text { discussed it on forehand }\end{array}$ \\
\hline Lighting use & 17 & $4 / 4$ & $\begin{array}{l}\text { 1B: When you want to make use of an area you will turn on the lamps there. But when we come in late } \\
\text { we just push any button }\end{array}$ \\
\hline $\begin{array}{l}\text { Selection and } \\
\text { installation process }\end{array}$ & 18 & $4 / 4$ & $\begin{array}{l}\text { 1A: For me [buying a luminaire] is about understanding the space: what do you do where and what } \\
\text { light do you need? }\end{array}$ \\
\hline Total & 104 & & \\
\hline
\end{tabular}

\subsection{Findings}

The study aims to identify real-life lighting conflicts within the home environment. People hardly self-reported any conflicts. Only one couple, for example, filled in the exercise about disagreements. Also the conversation exercise turned out to be difficult: people mentioned that conversations or contention about light are rare. Even during the interview, talking about light felt unnatural to people. However, by comparing the results from the booklet and confronting people with these differences during the interview, we identified multiple conflicts per couple. This suggests that, even though lighting conflicts exist, people often do not experience them as such.

\subsubsection{Three types of conflicts}

We identified three different types of conflicts: preference conflicts, activity conflicts, and attitude conflicts. The preference conflicts are situations where the couples are engaged in the same activity but prefer a different light setting for that activity.

\section{Participant I like the cinema feeling you get when all $1 B \quad$ lights are turned off. \\ Participant But I find it really difficult to watch TV when 1A it is dark. [...] I easily fall asleep.}

In most cases, people mentioned a general preference for brighter or dimmer light, or for a certain color 
temperature when comparing to their partner. Some preference conflicts occurred because of different opinions about a certain luminaire.

Activity conflicts arise because people simultaneously engage in different activities that have different lighting requirements. The most prominent examples are when one person goes to bed while the other still wants to read or when one person gets up earlier than the other. Less noticeable activity conflicts are, for example, when one person is watching TV while the other is reading:

Participant When I'm reading on the couch the ceiling $3 B \quad$ light is not enough, so then I turn the big lamp on. But you don't mind, right?

The third conflict type is attitude conflicts. Where the previous two conflicts only looked at lighting use, this conflict comes from a difference in attitude toward using light. For some people, energy awareness is more important than light quality, where for others the light quality is valued higher. For example, where one partner wants to turn off the lights they do not use for energy savings, the other partner finds it more important not to have any dark corners. In two of the four couples, we saw this difference between the partners leading to contention:

Participant Yesterday I was working here and you

$3 A \quad$ turned the lamps off. I like to have some extra light while working.

Participant But there was enough daylight! $3 B$

\subsubsection{Conflict impact and resolution}

Since people seem to have little awareness of lighting conflicts, observing resolution strategies was difficult. Lighting conflicts do not feel as very impactful to the social situation: the participants directly weakened any conflicts that came up in the interview. However, in the anecdotes and in the roles that they described for themselves and their partners, we were able to identify some distinctions between the three conflict types in resolution strategies and impact. Of the three types, preference conflicts seem to occur most often but seem the easiest to resolve:

Participant Whoever is bothered the most by the light is $2 A \quad$ the one that wins (...)

Participant Yes, when we watch television and you say: $2 B \quad$ "it is too dark, I'm falling asleep," we turn on some lamps.

When there is no difference in influence, the preference of the first person that set the light or that wants to put effort into adjusting the light is being used. Changing each other's light setting does not lead to conversations and seems to be fully accepted.

In activity conflicts, we see two different resolution strategies: changing activity and compromising for a less preferred light setting. Usually, people know who cannot compromise (e.g., when someone has to finish something for work and has to work late). It is up to the other person to change the activity in that case:

Participant If [partner] has to work late I stay up with $2 B \quad$ her, because I cannot sleep with the light on.

If such differences in activity happen over longer periods of time, people adjust their daily rhythms to match each other. The amount of influence that the difference in activity has on the other person determines its impact. In situations where the other person is less influenced by the light, compromising for a certain setting suffices.

The attitude conflicts are the only conflicts that we observed leading to disagreements or arguments, probably because there seems to be no real resolution strategy to this difference in values or attitude.

\subsubsection{Little variation in lighting use}

From the habits exercise, we could see that people have little variation in the way that they use lighting. Most people use one standard setting for their main lamps during the whole evening and add one specific lamp per activity to that setting (e.g., the kitchen lamp while cooking, or their desk lamp while working). This little variation in lighting use makes that few conflicts occur. It seems that the general use of lighting is established already in the process of selecting and buying lamps. In this process, people divide the room into functions and select luminaires that match these functions.

\section{Participant For me [buying a luminaire] is about 1A understanding the space: what do you do where and what light do you need?}

So with the selection process, the main preference and activity conflicts seem to be resolved: compromises are made between the different lighting preferences and the main function of a lamp (reading, watching TV, cooking) is defined. Because of this, people know what lighting they are entitled to use for each activity, which results in fewer conflicts:

Participant This is our compromise-lamp. I bought it to $2 A$ read in bed while [partner] wants to sleep. Our regular bedside lamp is too bright for that. 


\subsubsection{Limitations of the study}

We chose specifically this context of single-room apartments. Since people always share each other's light, we expected more lighting conflicts to occur. However, all couples mentioned that living together in a single room takes flexibility and less need for privacy or personal space. This could have influenced the low importance that people gave to the light, the few conversations, and the low awareness of conflicts. Furthermore, because of the popularity and fashionable style of the apartment building, the participant might have spent more time than average in decorating. This could mean that the importance of the lamp selection and buying process is higher in this specific target group.

Our main goal with this study was to confirm the existence of lighting conflicts, to find a selection of realistic lighting conflicts, and to get a first idea on their impact on the social situation. We did not necessarily aim to be complete in the conflict types or resolution strategies: the modest number of participants and the described homogeneous nature of the participant group make it unlikely that they are complete. Especially because the conflict triggers are related to people's routines and life-style (activity conflicts), personal preferences (preference conflicts), and attitudes (attitude conflicts) it is highly likely that different conflict types arise in different types of settings and with different participant groups. The importance of the conflicts is also likely to be conflict dependent and should not be generalized beyond the chosen context of single-room apartments.

\subsection{Conclusion}

In this study, we were able to distinguish three different types of lighting conflicts, characterized by their causes: preference, activity, and attitude conflicts. Preference conflicts (resulting from a different lighting preference for the same activity; similar to Deutsch's preferences and nuisance conflicts [29]) happen most often but seem most easy to resolve by compromising. Most of these compromises seem to be made already in the lamp selection and buying process (when a certain lamp is bought for that activity), which influences the possibilities of light use from then on, reducing future preference conflicts. Activity conflicts can have big impact when the lighting needs that match the activities are far apart (e.g., when one person wants to go to bed and prefers no light at all). They can be resolved by compromising in the light use or by matching activities or routines (e.g., going to bed later). Attitude conflicts (similar to Deutsch's values [29]) have less to do with the light situation and more with value differences on, in this case, energy saving vs. light quality. Manifested lighting conflicts [10] in general seem to be rare because of the relative low importance of lighting preferences and little variation in light use resulting from negotiations in the lamp selection process.

\section{Provoking conflicts in the family living room}

In the previous study, we observed lighting conflicts between couples in single-room apartments. Because of the little variation in use, limited control possibilities of traditional lamps, and flexibility of the specific target group, lighting conflicts remained in the background. Therefore, in this follow-up study, we use a more disruptive approach, where we actively try to provoke conflicts. We do so by (1) increasing the number of people involved (families instead of couples), (2) increasing the influence of lighting adjustments on other members of the families (by installation of a lighting system that introduces simultaneous control over all lamps), and (3) experimenting with different control distributions. By disrupting people's lighting routines and altering their use, we aim to make people reflect upon their normal ways of using light [27].

\subsection{Setup}

In this study, four families consisting of four to five persons (two parents and two or three children) took part, resulting in a total of 17 participants. The families were chosen such that the children ages are similar (ranging between 3 and 11 , median $=7$ ), and gender is evenly spread (female $=8$ ). Recruitment was done by word-of-mouth.

The approach of the study is based on technology probes $[28,52]$. In this method, technical probes are released in a real-life context to understand the needs and desires of users. The probes are designed to be flexible, adaptive, and open for interpretation: they do not embody a concept but they interfere with normal routines to make people reflect upon behavior, values, and attitudes [27]. Our technology probe (Fig. 3) consists of a connected lighting system with mobile dimmer controllers that adjust all lamps simultaneously; all lamps have the same brightness at all times. In this way, lighting adjustments influence all other family members.

The lighting system is based on the Philips Hue [5]. Four to six Hue bulbs replaced the original living room's light sources for the week of study. Where possible, people's regular fixtures were used, complemented with extra luminaires if needed. The number of light sources and the location of the luminaires were decided by the parents on installation. Mobile dimmer controllers were made to control the Hue light bulbs. The controllers were created for this study specifically and consist of a large scroll wheel 


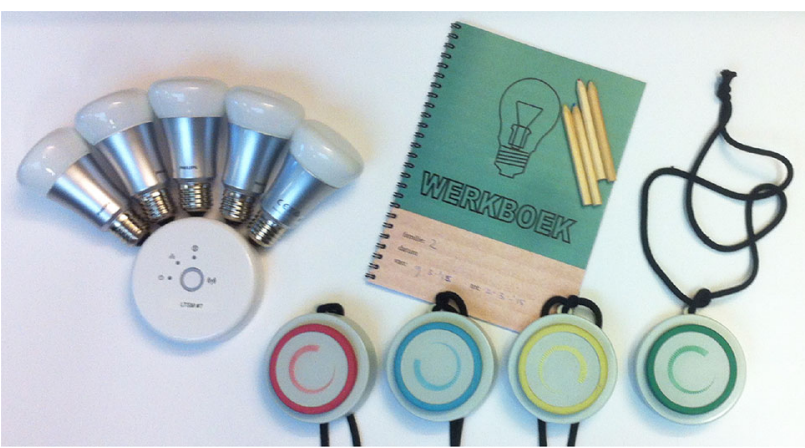

Fig. 3 Probe set, consisting of Philips Hue bulbs, mobile dimmer controllers, and a workbook

on a wearable pendant. By turning the wheel, people can adjust the brightness relatively to the current brightness of all the five Hue bulbs simultaneously. The set consists of four to five dimmer controllers with unique colors: one for every family member. The controllers communicate through XBee [56] with a processing sketch running on a laptop, which in its turn communicates through Wi-fi with the bridge of the Hue bulbs. The sketch logs date and time, controller ID, and the brightness values at each interaction. The study was executed in March, when the sun rises around 7 a.m. and sets around 6:30 p.m. The system is, therefore, mainly used from the early evening on.

\subsubsection{Procedure}

We specified three scenarios of use (Fig. 4). During scenario one (shared and fixed; Fig. 4a), participants are asked to store all controllers but one and to choose a fixed location for this controller. This scenario is most similar to the current usage of light switches. In the second scenario (personal and mobile; Fig. 4b), every participant had a controller. With this setting, we aim to identify the different roles between the family members in lighting use. We also wish to see whether individual and mobile control influences the threshold for making adjustments to the light. In the third and final scenario (shared and mobile; Fig. 4c), all controllers but one are stored again. The family was asked to select one person to wear the controller and the other members have to ask this person to adjust the light for them. With this scenario, we wish to trigger conversations about light. The families experimented with each scenario on two fixed days (Tuesday and Wednesday for the first, Thursday and Friday for the second, and Saturday and Sunday for the third), since we expect the weekend to have different routines and therefore different lighting use.

In order to capture personal experiences instantaneously, we supplied a diary-style workbook with exercises in Dutch. The exercises in the three chapters of the workbook correspond to the three use scenarios. The family was asked to fill in exercises together on the last day of each scenario. Exercises vary per chapter but always include drawing a timeline (Fig. 5a) and a drawing a conversation on light (Fig. 5b). As preparation for the interview, we analyzed the results from the workbook and from the log data (Fig. 6) to get an understanding of the light use. The interviews (all in Dutch) were held with the whole family together, lasted about $30 \mathrm{~min}$, and followed a semi-structured approach. We asked the family to compare the three different use scenarios, to explain remarkable instances from the $\log$ data and the workbook, and to discuss requirements for future lighting systems. The families received a symbolic token of appreciation for their participation in the study.

\subsubsection{Analysis}

The recorded audio from the interviews was transcribed. We extracted a total of 143 fragments (between 33 and 39 per interview) by reading the printed-out interviews multiple times and marking all relevant passages. The marked quotes were cut out, and used in an inductive thematic analysis [55]. We started with clustering the quotes into
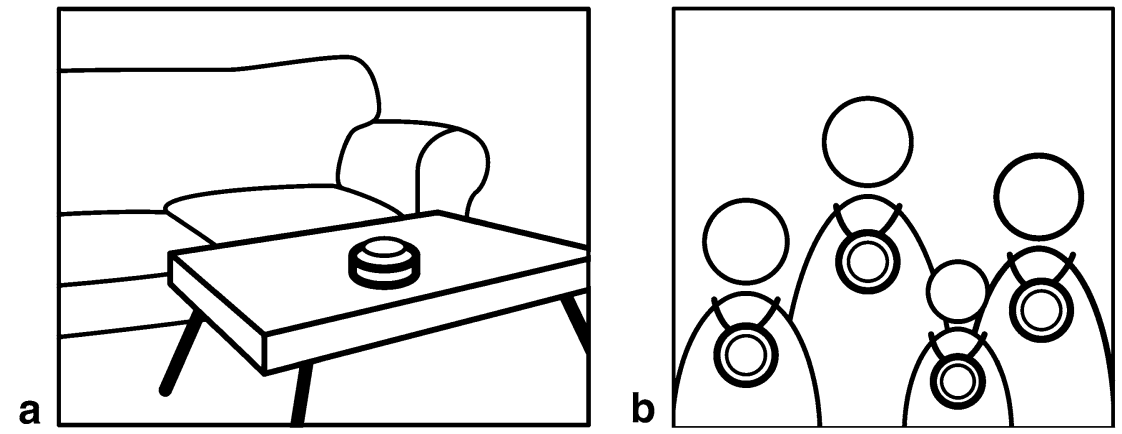

Fig. 4 a In the first scenario, one controller has a fixed location. b In the second scenario, every family member has its own mobile controller. c In the third scenario, only one family member has a

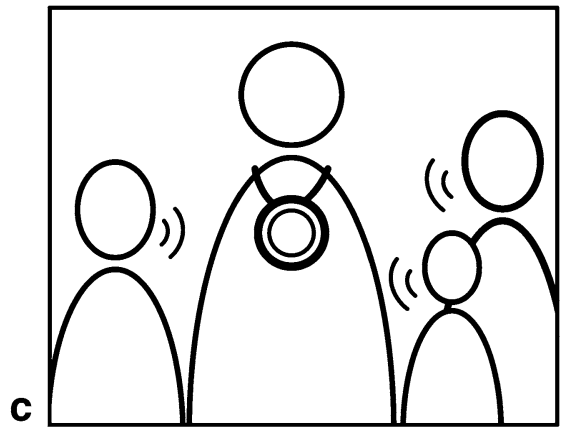

mobile controller. These drawings were used in the workbook to illustrate the scenarios of use 


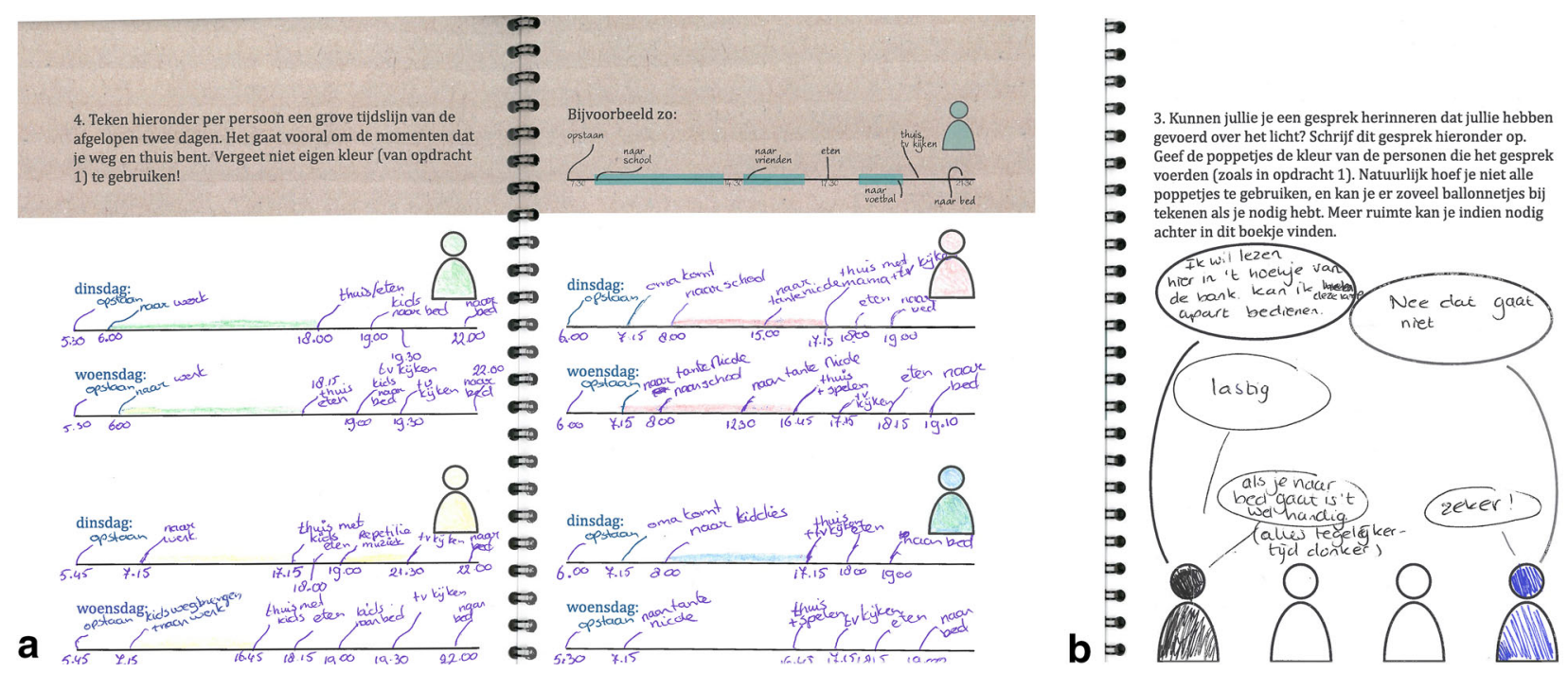

Fig. 5 Two of the exercises from the workbook: a the timeline exercise, indicating daily activities per family member (e.g., "waking up," "going to school," "dinner," "grandmother visits"), and b reporting on a conversation about light ("I want to read here on this side of the couch. Can I control this lamp separately?"- "No""That's a shame but it's convenient when going to bed."

a
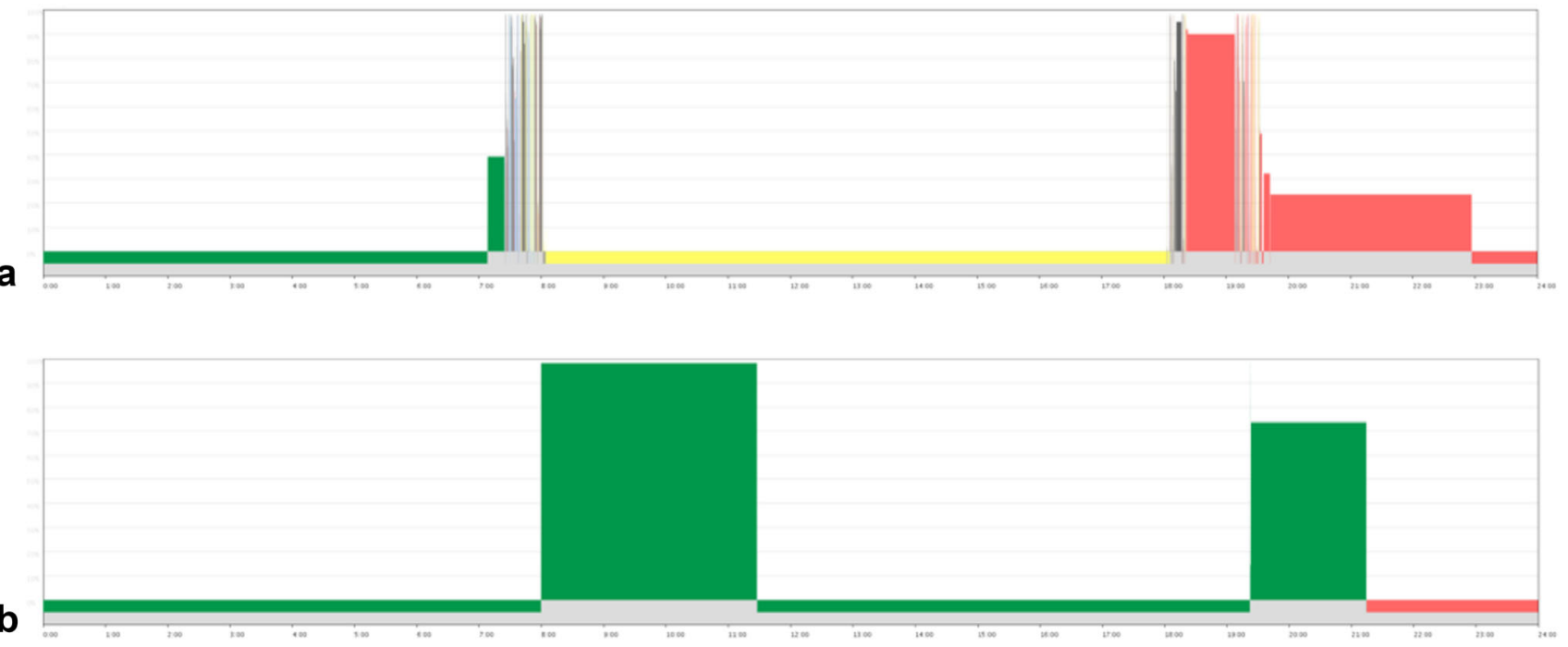

Fig. 6 Two graphs showing the log data: a the graph of Thursday (use scenario 2) from family 2 and $\mathbf{b}$ the graph of Sunday (use scenario 3) from family 4 . The color of the bar represents the color of the controller that was used. The height of the bar shows the brightness setting of the lamps (0-255). The width of the bar

bigger clusters (control, lighting appreciation, social roles, etc.). From there, we divided each larger cluster into smaller and more specific sub-areas. The clustering process was done iteratively and resulted in a total of 8 themes (Table 2). In discussions among all authors, high-level generalized conclusions were drawn for each theme. Just as in the first study, analysis was done with the original Dutch quotes. The quotes that are presented in this paper have been translated after analysis by the authors. represents the time in which the brightness setting was left unchanged. So in graph (a), moments of rapid changes to the light setting can be observed (disco playing), while in graph (b) there are only very few interactions with the light (color figure online)

\subsection{Findings}

In despite of the more disruptive and provoking setup compared to the previous study, we again found very little variation in lighting use. In general, the parent that was home most controlled the light most often. After the lamps were turned on, we observed very few adjustments in the log data (apart from the adjustments invoked by children playing around). Therefore, it seems that there is little 
Table 2 An overview of the themes resulting from the thematic analysis. The table presents the theme, the number of quotes per theme (\#), how many of the four families are represented in the theme (spread), and an example quote

\begin{tabular}{|c|c|c|c|}
\hline Theme & \# & Spread & Example quote \\
\hline Rules of use & 9 & $4 / 4$ & $\begin{array}{l}\text { Mother 1: We did not want any disco playing. Normally, they are not allowed to play with the light, so we } \\
\text { decided that during this study they should not either }\end{array}$ \\
\hline Social behavior & 25 & $4 / 4$ & $\begin{array}{l}\text { Boy 1: My sister used it more often than dad, because whenever I turned the light off, [my sister] would } \\
\text { turn it on again }\end{array}$ \\
\hline System use & 19 & $4 / 4$ & $\begin{array}{l}\text { Father 1: There is a difference between children and adults. Children turn the knob, while adults adjust } \\
\text { the light. We don't play like children do }\end{array}$ \\
\hline Lighting use & 14 & $4 / 4$ & $\begin{array}{l}\text { Father 3: When I come home it is dark so the lamps are already turned on. There should be a practical } \\
\text { reason to change the light otherwise it is just fine. It is just turned on }\end{array}$ \\
\hline Simultaneous control & 12 & $4 / 4$ & $\begin{array}{l}\text { Father 3: We didn't change [the light] that much, because adjusting one meant that all would change. So } \\
\text { then you just leave it like that }\end{array}$ \\
\hline $\begin{array}{l}\text { Mobile and fixed } \\
\text { control }\end{array}$ & 22 & $4 / 4$ & Boy 3: This one [scenario 1] was easier. [...] I guess because you know exactly where it was \\
\hline $\begin{array}{l}\text { Individual and shared } \\
\text { control }\end{array}$ & 16 & $4 / 4$ & Boy 1: When I have a controller for myself, I think about [adjusting the light] more \\
\hline Limitations & 26 & $4 / 4$ & Mother 2: It has to respond instantaneously. Now it often took too long \\
\hline Total & 143 & & \\
\hline
\end{tabular}

variation in lighting use and little incentive to change an already satisfying light setting.

We expected that the simultaneous control over all light bulbs would increase the number of lighting conflicts, since it enlarges the influence that people have on each other with individual lighting interaction. What we observed, however, is that it led to even less use of the system: sometimes because of energy consumption (turning on one lamp turns on all other lamps, so they waited until it got really dark to turn the lights on) but, more interestingly, also because people did not feel entitled to adjust lights that are also used by others and did not want to influence others negatively.

Father We didn't change [the light] that much, because 3 adjusting one meant that all would change. So then you just leave it like that.

\subsubsection{Conversations and conflicts}

Also similar to the results from the previous study, people found it difficult to talk about the lighting use in the interview. Also during the study, little conversations were reported. We expected that especially use scenario three (presenting shared and mobile control) would inspire conversation about the light, since people had to ask each other to make adjustments. However, none of the conversation exercises in the booklet for the third use scenario were filled in. From the other exercises it became clear that few people requested adjustments at all: in the three families where one of the parents had the controller (families 1, 3 , and 4), there were in total only two requests from others. People mentioned that the adjustment did not matter enough to bother others with the request and that it felt unnatural to ask for an adjustment:

Father When I had the controller, nobody asked me to $1 \quad$ change the light.

Boy 1 No, because that is stupid. We never ask you to change the light.

Of the conversations that were filled in, most talked about the system's usability. Simultaneous control over all lamps, reaction time, and controller size were the topics in 7 out of 12 reported conversations. Of the remaining conversations, four conversations were about interpersonal disagreement. Of those, two had more to do with playing around than with the light itself but three focused around lighting conflicts. One conversation described a difference in liking of a certain setting (preference conflict):

Father 1 this light is way too bright.

One conversation described different lighting needs for simultaneously performed activities (activity conflict):

Father I want to read here, on the couch. Can't I change $3 \quad$ this lamp individually?

And one conversation described a disagreement about energy use (attitude conflict):

Girl $4 \quad$ May I turn the light on at my desk?

Mother "No honey, because that will make the other $4 \quad$ lamps turn on as well."

So in total we identified three instances of lighting conflicts: one per conflict type. 


\subsubsection{Hierarchy and rules of use}

When looking at the log data from the families, we identified two distinct ways of using the light: in two of the families, there was very little variety in the lighting use (Fig. 6b); while in the other two families, we observed several hours with rapid changes in the light setting, especially with the controllers owned by the children (Fig. 6a). In the interviews the difference was explained. Two families (families 3 and 4) had made the rule that playing with the light was not allowed. The other two families (families 1 and 2) decided to let their children play for the sake of the study. Important to note is that this was seen as an extraordinary situation:

Father We did let go of the children for this week. The 1 time was relatively short, and you come home at 6, it gets dark around 6:30, and the first ones go to bed already at 7:30.

This rule difference had a big consequence on the quantitative data and on the impact of the different use scenarios on the use of lighting. In the families without rules, the system was used more often and the difference between the use scenarios was larger, especially with use scenario two (personal and mobile control).

These rules illustrate the strict hierarchy in lighting use within the families. Parents have the final say about the light setting and about the way that the children use the light. Children know this difference in roles and what is expected of them.

\section{Boy 3 When one person is reading in the corner and the other is watching TV, one wants darkness while the other one wants light. \\ Interviewer So how would that situation be solved? \\ Girl 3 The person that is reading would win, because that is usually dad.}

It seems that in many cases possible conflicts (where the children, e.g., potentially have a different preference than the parents) are resolved before they even come to light: the children know that they will not be allowed to change the light, which makes that they do not even evaluate their preference anymore. Interestingly, none of the parents wanted the system to limit control possibilities of the children. They mentioned that what lighting adjustments children are entitled to is too dynamic for fixed hierarchies.

Mother The control doesn't have to be shielded of from 2 the children. We make sure ourselves that they will stay away from it. And if they are playing in the back, and controlling the lights themselves, I am also fine with that.

\subsubsection{Control distributions in the use scenarios}

We presented the families with three different use scenarios with different control distributions, to see whether control influences lighting use and conflicts. Use scenario one prescribed a fixed controller location, where scenario two and three presented mobile control. We found that mobile control reduced the effort to change the light setting and its presence reminded people of the ability to control the light. Because of both these factors, the light is more often adjusted with mobile control.

Mother If [the controller] had been located at the table, 2 I probably wouldn't have adjusted it. (...) When I see the controller, it reminds me that the light is actually a bit too bright, that it could be dimmed down a bit.

In scenario two, the family members each had an individual controller, where in scenario one and three control is shared. This difference was less visible for the participants, especially for the parents:

Father In the end I use it in the same way. If I want to $1 \quad$ change the light, I turn the knob and that's it.

The individual control did seem influence the children's use of the controller. Having individual control seems to lead to a feeling of ownership and, therefore, to more interaction:

Boy 1 When I have a controller for myself, I think about [adjusting the light] more.

The parents did not appreciate this increase of interaction:

Mother Well at some point you define a certain intensity 1 of the light but that can be changed back within seconds. In real life it is not really like that. The threshold to change the light is much bigger then.

However, this effect might diminish over time. Parents did notice a decrease in interest from the children, already during the two-day use scenario:

Father In the end we found a nice setting for the light. 2 (...) Playing disco is only fun for a while.

So the control distributions that were presented through the different use scenarios (mobile vs. fixed location, and individual vs. shared) did have some influence on the light use, especially in the feelings of ownership and entitlement of the children, the number of interactions, and the availability of the controller. However, these effects were overshadowed by the rules of use defined by the parent-child hierarchy. 


\subsubsection{Limitations of the study}

In comparison with the previous study, the selected participant group might have influenced low number of observed conflicts. Since the parents all have been living together longer, preferences might be even more aligned than with the couples from study that moved in together recently. Also, from the timeline exercises it became clear that parents hardly perform different activities simultaneously in the living room. Therefore, activity conflicts are less likely to happen. Between children and parents differences in simultaneously performed activities do occur but here the hierarchy resolves conflicts, as discussed before.

The rules of use (whether playing with the light is allowed or not) had a major influence on the way in which the system was used. For this study, this gives interesting insights on family structure and hierarchy. However, now that we know this influence, it might be good to give more instruction to the families about the expected behavior in next studies.

The lighting system that we used depended on the Internet infrastructure of the families, which in some cases (2/4 families) resulted in an undesired delay between interaction and response from the lamps. With one family, the response time was exceptionally long and could sometimes take up to $5 \mathrm{~s}$. Participants mentioned that this malfunctioning lead to less interaction with the light out of frustration. In general, we observed less interaction than expected. We implemented certain features like the simultaneous control in the lighting system to provoke conflicts between the family members. What we observed, however, is that these features often raised conflicts and contention between the family as a whole and the system's possibilities. People sometimes did not seem to bother adjusting the light, since they would probably not be able to adjust it to their likings anyway. We expect that the before mentioned delay also contributed to this shift from conflicts between family members to conflicts between family and system. In future studies, we intend to use a lighting system that does not depend on the local internet infrastructure for its communication.

All together the moderate number of participants, as well as the narrow group (middle class Dutch families) with similar types of houses and lighting uses, has influenced the results of this study. Our insights on resolution strategies (e.g., related to family hierarchy or conversations) are likely to differ between families of different social or cultural backgrounds.

\subsection{Conclusions}

In this study, we aimed to observe the triggers, social implications, and resolution strategies for lighting conflicts within the home environment. Since lighting conflicts in the home environment normally seem to be rare and invisible, we wanted to provoke conflicts by (1) increasing the number of people involved (families of 4-5 people), (2) increasing the influence of lighting adjustments on other members of the families (through simultaneous control over all lights), and (3) experimenting with different control distributions. The most remarkable result of this study is that still few lighting conflicts occurred. A strong hierarchy between parents and children, resulting in rules of use, strictly control the usage of the light system. This hierarchical relationship between parents and children is in line with findings from previous studies on home technology sharing $[36,38]$ and clearly defined roles are known to reduce conflict [57]. Also, because of the designed triggers, people interacted even less with the light to avoid possible conflicts or undesired influence on others. This was also found by Offermans et al. [23]. The interpersonal conflicts, even though small in number, matched the conflict types of the previous study: we observed a preference, an activity, and an attitude conflict. The resolution of these conflicts was mainly based on hierarchy (parents decide). Talking about light, even when provoked by the system and by the scenarios, still felt unnatural to people.

\section{Perspective on multi-user interaction in the home environment}

The two studies that are presented in this paper aim to give a better understanding of everyday lighting conflicts in the home environment. In this section we discuss what the insights mean when designing multi-user interaction with connected lighting systems. We present our perspective on designing for multi-user lighting interaction, in order to make interfaces that fit people's natural ways of using light and resolving conflicts. We first project our findings on connected lighting systems to identify the role that conflicts should play in interaction design. We then describe how interaction designers can approach conflicts by presenting a strategy based on providing information about other users through the interface. Lastly, we specify for each of the three conflict types (preference, activity, and attitude conflicts) what information can be shared in the interface to help people estimate the impact of their interaction on others.

\subsection{Expected increase of conflicts with modern lighting systems}

In general, few manifested lighting conflicts seem to happen in the home environment that we investigated. This can be explained by the fixed lighting routines and little 
variation in lighting use that we observed, which is in line with findings by Offermans et al. [23]. People's lighting routines seem to be established by agreements, which are already made when the lamp is selected during the interior decoration process: by deciding on the light source, fixture, and location of the lamp people make compromises that determine later use. In modern lighting systems, however, these prior agreements are not necessary anymore. Since brightness, color (temperature), and possibly even spread, direction, or focus could be adjusted at any moment there is no need for prior negotiation: each decision can be revisited at any time. As a result, we expect that compromises are no longer made on installation but in the moment of use. Also, since negotiation at purchase is no longer required, people might have less knowledge of each other's needs and wishes in light. And since every decision can be revisited, we expect that people will have raised expectations of the lighting quality. So even though conflicts are currently rare and highly latent, we expect that their number will increase with modern lighting systems. This is not necessarily negative. As Deutsch [29] mentioned, conflict can stimulate creativity, result in better understanding, and is the start for change: all effects that are clearly desirable when modern lighting systems open up many more possibilities in use.

\subsection{Conflict situations require awareness}

So how should we approach the conflicts in interaction with modern lighting systems? The conflicts that were observed in this study seem to remain latent. We found that people often do not experience conflicts as such: compromises are made easily, without the need for a conversation or negotiation to resolve the conflict. It seems that people are very skilled in estimating what behavior is found appropriate, using cues from the social context [58]. This insight describes a risk for conflict-managing systems that aim to automatically recognize and resolve conflicts (e.g., $[16,20,21])$ : if a system adjusts the light to mediate between user preferences in profiles, while people have already resolved that conflict among each other, these systems might actually create conflicts they intend to resolve. Therefore, we believe that recognizing conflicts and resolving those conflicts should be left to the user.

Giving control to people in conflict resolution does not mean that conflicts should not be taken into account in interaction design. Easterbrook already described how "technology necessarily influences styles of cooperation, by making some things easier and other things harder to do" ([10], p. 2). Also, Offermans et al. [23] found that people do not like to disturb others with their light. We draw a similar conclusion: in situations when there is a risk that others might be bothered by the adjustment, people compromise by not adjusting the lighting at all, even though adjusting the light might lead to better lighting. So while flexible lighting use is seen as a main advantage of modern lighting, people have the tendency to not adjust the lighting because of the risk of evoking conflicts. As mentioned, we expect that in future lighting systems people have even less awareness of each other's needs and wishes, which would increase the insecurity in adjusting the light even more. So if we want people to make the most of modern lighting systems, people need to be informed about each other's needs and preferences and about the impact an individual adjustment has on other users, to remove the insecurity of having a negative impact while adjusting the light. As Randall also showed: "Issues of control cannot be reduced to cognitive load. They include not only the individual's sense of being able to use the technology, but also the sense of control that comes from knowing what others are doing or have done with the same technology. It appears that significant feedback is necessary if that sense is to be maintained." [35, p. 243].

Providing information that helps for mutual awareness in interaction is a natural coordination strategy to people: this is what Taylor calls the smartness of objects [42]. Designing such information explicitly into the interface to support distributed multi-user interaction, has been proposed by Erickson and Kellogg [58] in their Social Translucence framework. The framework, originating from Computer-Mediated Collaborative Work (CSCW) interfaces, describes through three constructs (visibility, awareness, and accountability) how people use information from their surroundings to judge what appropriate behavior is. Visibility of information in an interface provides awareness of each other's actions, the intentions behind them, and the effect that interactions can have on others. Because of this understanding of action and reaction by all users, people feel accountable for their actions. So by providing visibility of information, to create awareness about the other users in the interface at the moment of interaction, people can better estimate what impact their adjustments will have on others. We argue that this strategy is not only valuable in distributed interaction but also in collocated interaction where people need to estimate whether their behavior is appropriate. By providing the right information at the right moment, insecurity of the user will decrease, leading to better lighting conditions and fewer conflicts.

\subsection{Information requirements per conflict type}

So in line with $[41,42,58]$ we see a promising direction for multi-user interaction in giving control and initiative to users while supporting them with information about other users. But what information is needed to estimate the 
appropriateness of a certain lighting adjustment? In the studies that are presented in this paper, we identified three types of lighting conflicts resulting from a difference in preference, activity, or attitude. We can use these conflict types to specify what information needs to be visualized in the interface to create awareness and accountability among all users.

\subsubsection{Preference conflicts}

Preference conflicts result from a difference in lighting preference while performing the same activity. Preference conflicts did not seem to have a large impact on the social setting in our studies and were easy for users to resolve through compromise. We found that usually the preferred light setting of the person that wants to put effort into adjusting the light is used. Therefore, the moment when a user feels dissatisfied with the lighting condition and he/she takes the initiative to adjust the light is when the information about the other users needs to be provided.

We especially think that information about the motivation for the currently selected setting can help the user in estimating what he/she is entitled to adjust, since what adjustments others find appropriate depend highly on how the current setting is valued and should remain unchanged. One important indicator of that could be the effort that was put into creating the light setting. For example, if the current light setting was established by selecting a standard preset, this took far less effort than when the current lighting setting was established by selecting every individual lamp and adjusting each of its parameters. So while large adjustments to the preset are probably accepted (it has been set with little effort and is easy to restore), adjustments to the custom setting should be considered more carefully. So sharing information about the process of establishing the current setting could help in estimating the extent to which adjustments are appropriate. This could also be done more explicitly, by requesting users to indicate during the interaction whether they would like the setting to be left unchanged. Think, for example, of giving the opportunity to shield, hide, or safeguard controls, so that they are not directly accessible by the next user. Another possibility is to give users information about the current relevance of the previous setting. For example, by communicating for how long a setting has been applied: adjustments to a setting that has been applied hours ago might be more acceptable than adjustments to a more recent setting.

In contrast to presenting information about the currently selected light setting, providing information about what others might like regardless of whether they have set the light previously or not, could also be an option. For example, the color palettes that are generally used by other users could be supplied. Or the interaction history of other users in similar situations could be provided, to base the decision for a new light setting upon.

\subsubsection{Activity conflicts}

Activity conflicts arise when people simultaneously engage in different activities that have different lighting requirements. They are currently resolved by compromising in light use or by synchronizing activities. Interfaces could support compromising by informing people about the other activities that are taking place in the room at the moment of interacting with the light. For example, if presets are labeled as activities as is often done, the selected preset indicates the intention people have with the selected light setting. Since the compromise strategies often look at priorities of certain activities over others, adjustments to the preset "watching TV" could be more acceptable than adjustments to the "study" preset, for example. Another way to present information about activities could be to distribute interaction over the living room: when people need to be in the area where adjustments are made, they will automatically receive information about the context, other people being present, and other activities taking place. This contextual information could be transferred again to a globally shared interface, which could present which areas and lamps in the room are currently being used.

Another possibility is to place responsibility for preventing conflicts with the person that requires the light for a certain activity, instead of with the person that is making adjustments. For example, it could be possible to disconnect a particular lamp or area of the room, to make them not respond to global adjustments. In this way, the person requiring this specific light could prevent unwanted changes and conflicts to happen. Since anticipation to changing activities seems to be important to activity conflicts (if an activity only takes a little while, people might not be bothered with less optimal lighting conditions, while for longer activities another compromise might be more suitable), the disconnection could be linked to a certain amount of time, for example.

\subsubsection{Attitude conflicts}

Attitude conflicts are the result of differences in what value is given to, e.g., lighting quality and energy consumption. These conflicts seem to be most difficult to resolve. We believe that interfaces could play a role in raising awareness of the difference in attitude and understanding of each other's arguments. For example, energy data could be visualized to make a more informed decision: maybe, a dim light to brighten up dark corners does not consume as 
much energy as expected. Or maybe turning off the bright hallway light saves so much energy that leaving it on seems more of a waste. Also, people could actively indicate their preferred balance between energy consumption and lighting quality and with this indication, influence the maximum values for, e.g., brightness levels or timers.

The only moment we really observed contention about light use was in situations where one person (in our examples the less energy aware partner) forgot to turn off the lights when leaving the house. While this is strictly not a conflict, it seems to be much related to the attitude difference creating attitude conflicts. Lighting interfaces could remind people of turning off the light when they leave the house, e.g., by becoming more present when people leave the room, or by presenting the option to turn off every lamp in the home in the hallway.

We have presented a perspective on lighting interface design, describing how presenting socially relevant information about the other users of a system could support interaction. Based upon the three types of lighting conflicts, concrete examples of information types were given. We see the perspective as a starting point for the design of a new generation of multi-user interfaces for domestic lighting systems.

\section{Conclusions}

The work presented in this paper brings a new perspective on multi-user interaction with domestic connected lighting systems, based on a better understanding of real-life conflict situations. We argue that multi-user interaction should build upon natural ways in which people handle conflicts in their everyday routines, in order to make the interaction fit into social context. To inform strategies for multi-user interaction with domestic connected lighting systems, we have presented insights resulting from two studies: one on conflicts on lighting in the home environment and one on social resolution strategies in family living rooms. The results from the studies suggest that there are different types of conflicts, resulting from a difference in preference, activity, or attitude. We also found that people are very able to (unaware) avoid conflicts even in situations where conflicts are provoked. Often, they do so by not adjusting the light at all.

Based on these insights, we defined a perspective on multi-user interaction in conflict situations. We confirmed the importance of explicit user control, to not create conflicts that are already resolved. Also, instead of focusing on the existence of a conflict, systems and their interfaces should focus on providing the user with the confidence to interact. To help people in using connected lighting systems to their full, interactive, flexible, and dynamic potential, interfaces need to assure users that interactions are socially accepted. This assurance can be given by presenting the user with information about the acceptance of a lighting change by the other users, through the interface. We have demonstrated how the insights into different types of real-life lighting conflicts can be used to define what information needs to be visualized in the interface. This combination of a deeper understanding of lighting conflicts and a perspective on lighting interface design is a starting point to design better multi-user interfaces for domestic lighting systems.

Acknowledgements We thank the participants of our two studies for their time, effort, and enthusiasm. We appreciate their openness and the peek that they gave us into their daily lives. We are indebted to the anonymous reviewers whose constructive feedback helped to improve this paper. This research was performed within the joint research program on Intelligent Lighting between TU/e and Koninklijke Philips N.V.

Open Access This article is distributed under the terms of the Creative Commons Attribution 4.0 International License (http://crea tivecommons.org/licenses/by/4.0/), which permits unrestricted use, distribution, and reproduction in any medium, provided you give appropriate credit to the original author(s) and the source, provide a link to the Creative Commons license, and indicate if changes were made.

\section{References}

1. Bose wireless speakers. https://www.bose.com/products/speak ers/wireless_speakers.html. Accessed 2 Dec 2016

2. Sonos HiFi wireless speakers and home audio systems. http:// www.sonos.com/. Accessed 2 Dec 2016

3. Belkin WeMo Home Automation. http://www.belkin.com/us/ Products/home-automation/c/wemo-home-automation/. Accessed 2 Dec 2016

4. Nest Nest thermostate. https://nest.com/thermostat/meet-nestthermostat/. Accessed 2 Dec 2016

5. Philips Hue. http://www2.meethue.com/en-XX/. Accessed 2 Dec 2016

6. LIFX Live a more illuminated life. http://www.lifx.com/. Accessed 2 Dec 2016

7. Philips Hue Tap. http://www2.meethue.com/en-us/productdetail/ philips-hue-tap-switch. Accessed 2 Dec 2016

8. m-Qbe. http://m-q.be/. Accessed 2 Dec 2016

9. Lucero A, Lashina T, Terken J (2006) Reducing complexity of interaction with advanced bathroom lighting at home (Reduktion der Interaktionskomplexität bei hochentwickelten Badezimmerbeleuchtungssystemen für die Heimanwendung). i-com 5:35-40. doi:10.1524/icom.2006.5.1.34

10. Easterbrook SM, Beck EE, Goodlet JS et al (1993) a survey of empirical studies of conflict. In: Easterbrook SM (ed) CSCW coop or conflict?. Springer, London, pp 6-68

11. Lucero A, Mason J, Wiethoff A et al (2016) Rethinking our interactions with light. Interactions 6:54-59. doi:10.1145/ 3003334

12. Magielse R, Hengeveld B, Frens J (2013) Designing a light controller for a multi-user lighting environment. In: Proceedings 
5th international congress of the International Association of Societies of Design Research (IASDR)

13. Knoop M (2006) Dynamic lighting for well-being in work places: Addressing the visual, emotional and biological aspects of lighting design. In: Proceedings 15th international symposium on light engineering, Venice, Italy, pp 63-74

14. Niemantsverdriet $\mathrm{K}$, Broekhuijsen $\mathrm{M}$, Essen $\mathrm{H}$ van, Eggen $\mathrm{B}$ (2016) Designing for multi-user interaction in the home environment: implementing social translucence. In: Foth $\mathrm{M}, \mathrm{Ju} \mathrm{W}$, Schroeter R, Viller S (eds) DIS 2016 Proceedings of the 2016 ACM Conference on Designing Interactive Systems. ACM, Brisbane, pp 1303-1314

15. Poole MS, Homes M, DeSanctis G (1988) Conflict management and group decision support systems. In: Proceedings 1988 ACM conference on computer cooperative crop. Work-CSCW '88. ACM Press, New York, USA, pp 227-243

16. Al-Bin-Ali F (2004) Design principles for inducing reactivity in ubiquitous environments. In: IEEE/ACS International conference on pervasive services, IEEE, pp 131-139

17. Hasan MK, Pham Ngoc KA, Lee Y-K, Lee S (2009) Preference learning on an OSGi based home gateway. IEEE Trans Consum Electron 55:1322-1329. doi:10.1109/TCE.2009.5277995

18. Huerta-Canepa G, Lee D (2012) A multi-user ad-hoc resource manager for public urban areas. Technol Innov Adapt Dependable Syst. doi:10.4018/978-1-4666-0255-7.ch004

19. Park I, Lee D, Hyun SJ (2005) A Dynamic context-conflict management scheme for group-aware ubiquitous computing environments. In: 29th Annual International Computer Software and Applications Conference, vol 1, pp 359-364. doi: 10.1109/ COMPSAC.2005.21

20. Shin C, Woo W (2005) Conflict resolution based on user preference and service profile. IPSJ SIG Tech Rep 2005:311-316

21. Shin C, Woo W (2009) Service conflict management framework for multi-user inhabited smart home. J-Jucs 15:2330-2352. doi:10.3217/jucs-015-12-2330

22. Lichtenstein S, Slovic P (2006) The construction of preference. Cambridge University Press, Cambridge

23. Offermans S, van Essen H, Eggen B (2014) User interaction with everyday lighting systems. Pers Ubiquitous Comput 18:2035-2055. doi:10.1007/s00779-014-0759-2

24. Edwards WK, Grinter RE (2001) At home with ubiquitous computing: seven challenges. In: Brumitt $\mathrm{B}$, Shafer $\mathrm{S}$ (eds) Abowd GD. Springer, Berlin, pp 256-272

25. Davidoff S, Lee MK, Zimmerman J, Dey A (2006) Sociallyaware requirements for a smart home. In: Proceedings of the international symposium on intelligence environment, pp 41-44

26. Hindus D (1999) The importance of homes in technology research. In: Streitz NA, Siegel J, Hartkopf V, Konomi S (eds) Coopoerative build. Integrating information, organizations and architecture. Springer, Berlin, pp 199-207

27. Poole ES, Comber R, Hoonhout J (2015) Disruption as a research method for studying technology use in homes. Interact Comput 27:13-20. doi:10.1093/iwc/iwu035

28. Hutchinson H, Mackay W, Westerlund B et al (2003) Technology probes: inspiring design for and with families. ACM, New York, pp 17-24

29. Deutsch M (1977) The resolution of conflict: constructive and destructive processes. Yale University Press, New Haven

30. Resendes S, Carreira P, Santos AC (2014) Conflict detection and resolution in home and building automation systems: a literature review. J Ambient Intell Humaniz Comput 5:699-715. doi:10. 1007/s12652-013-0184-9

31. Shin C, Dey AK, Woo W (2010) Towards combining automatic resolution with social mediation for resolving multiuser conflicts. Cybern Syst 41:146-166. doi:10.1080/01969720903584282
32. Nacci AA, Balanji B, Spoletini P et al (2015) BuildingRules: a Trigger-action based system to manage complex commercial buildings. In: UBICOMP/ISWC'15 Adjun. Osaka, pp 381-384

33. Ur B, McManus E, Pak Yong Ho M, Littman ML (2014) Practical trigger-action programming in the smart home. In: Proceedings 32nd annual ACM conference on Human factors computer system CHI'14. ACM Press, New York, USA, pp 803-812

34. Meerbeek B, te Kulve M, Gritti $T$ et al (2014) Building automation and perceived control: a field study on motorized exterior blinds in Dutch offices. Build Environ 79:66-77. doi:10. 1016/j.buildenv.2014.04.023

35. Veitch JA (2001) Psychological processes influencing lighting quality. J Illum Eng Soc 30:124-140. doi:10.1080/00994480. 2001.10748341

36. Frohlich D, Kraut R (2003) The social context of home computing. In: Harper R (ed) Insid. Smart home. Springer, London, pp $127-162$

37. Mateas M, Salvador T, Scholtz J, Sorensen D (1996) Engineering ethnography in the home. Conf Hum Factors Comput Syst. doi:10.1145/257089.257323

38. Brush AJB, Inkpen KM (2007) Yours, mine and ours? sharing and use of technology in domestic environments. In: UbiComp'07 proceedings 9th international conference on ubiquitous computer. Springer, Berlin, pp 109-126

39. Chetty M, Banks R, Harper R, et al (2010) Who's Hogging the bandwidth?: The consequences of revealing the invisible in the home. In: CHI2010 Proceedings SIGCHI conference on Human factors computer system. ACM, pp 659-668. doi: http://doi.acm. org/10.1145/1753326.1753423

40. Crabtree A, Rodden T (2004) Domestic routines and design for the home. Comput Support Coop Work CSCW Ann Int J 13:191-220. doi:10.1023/B:COSU.0000045712.26840.a4

41. Randall D (2003) Living inside a smart home: a case study. In: Harper R (ed) Insid. Smart home. Springer, London, pp 227-246

42. Taylor AS, Harper R, Swan L et al (2007) Homes that make us smart. Pers Ubiquitous Comput 11:383-393. doi:10.1007/s00779006-0076-5

43. Insider C (2013) Goldee smart light controller. http://www. crowdfundinsider.com/2013/11/27263-goldee-worlds-smartestlight-switch-crowdfunding-now/. Accessed 4 Dec 2016

44. Fonckel One (2012). https://www.youtube.com/watch?v= D7kvXDhbRUM. Accessed 4 Dec 2016

45. Westerhoff J, van de Sluis R, Mason J, Aliakseyeu D (2012) M-beam: A tangible atmosphere creation interface. Proc Exp, Light Conf

46. Ross P, Keyson DV (2007) The case of sculpting atmospheres: towards design principles for expressive tangible interaction in control of ambient systems. Pers Ubiquitous Comput 11:69-79. doi:10.1007/s00779-005-0062-3

47. Heun V (2015) Reality Editor. http://www.valentinheun.com/ portfolio/reality-editor-smarter-objects/. Accessed 4 Dec 2016

48. Bakker S, Niemantsverdriet K (2016) The interaction-attention continuum: considering various levels of human attention in interaction design. Int J Des 10:1-14

49. Brumitt B, Cadiz JJ (2001) Let there be light examining interfaces for homes of the future. In: Proceedings of the IFIP INTERACT01 human-computer interact, Tokyo, Japan, pp 375-382

50. Brumitt B, Meyers B, Krumm J et al (2002) EasyLiving: technologies for intelligent environments. In: Thomas P, Gellersen $\mathrm{H}-\mathrm{W}$ (eds) Hendheld ubiquitous computer. Springer, Berlin, pp 12-29

51. Lucero A, Lashina T, Diederiks E, Mattelmäki T (2007) How probes inform and influence the design process. In: Proceedings 
of the 2007 conference on designing pleasurable product interfaces. DPPI'07 377. doi: 10.1145/1314161.1314195

52. Mattelmäki T (2005) Applying probes-from inspirational notes to collaborative insights. CoDesign 1:83-102. doi:10.1080/ 15719880500135821

53. Boehner K, Vertesi J, Sengers P, Dourish P (2007) How HCI interprets the probes. In: CHI'07 proceedings of the SIGCHI conference on human factors computer system. ACM, New York, USA, pp 1077-1086

54. Visser FS, Stappers PJ, van der Lugt R, Sanders EB-N (2005) Contextmapping: experiences from practice. CoDesign 1:119-149. doi:10.1080/15710880500135987
55. Braun V, Clarke V (2006) Using thematic analysis in psychology. Qual Res Psychol 3:77-101. doi:10.1191/1478088706qp063oa

56. Digi International XBee. http://www.digi.com/lp/xbee/. Accessed 4 Dec 2016

57. Baker PM (1981) The division of labor: interdependence, isolation, and cohesion in small groups. Small Gr Res 12:93-106. doi: $10.1177 / 104649648101200107$

58. Erickson T, Kellogg WA (2000) Social translucence: an approach to designing systems that support social processes. ACM Trans Comput Interact 7:59-83. doi:10.1145/344949.345004 